\title{
Determinants and risk factors of gastroenteritis in the general population, a web-based cohort between 2014 and 2017 in France
}

Marie Ecollan ${ }^{1,2}$, Caroline Guerrisi ${ }^{1}$, Cécile Souty ${ }^{1}$, Louise Rossignol ${ }^{1,3}$, Clément Turbelin ${ }^{1}$, Thomas Hanslik ${ }^{1,4,5}$, Vittoria Colizza ${ }^{1}$ and Thierry Blanchon ${ }^{1 *}$ (D)

\begin{abstract}
Background: Although it is rarely fatal in developed countries, acute gastroenteritis (AGE) still induces significant morbidity and economic costs. The objective of this study was to identify factors associated with AGE in winter in the general population.

Methods: A prospective study was performed during winter seasons from 2014 to 2015 to 2016-2017. Participants filled an inclusion survey and reported weekly data on acute symptoms. Factors associated with having at least one AGE episode per winter season were analyzed using the generalized estimating equations (GEE) approach.

Results: They were 13,974 participants included in the study over the three seasons. On average, $8.1 \%$ of participants declared at least one AGE episode during a winter season. People over 60 declared fewer AGE episodes (adjusted $\mathrm{OR}(\mathrm{aOR})=0.76,95 \% \mathrm{Cl}[0.64 ; 0.89])$ compared to individuals between 15 and 60 years old, as well as children between 10 and $15(\mathrm{aOR}=0.60[0.37 ; 0.98])$. Overweight $(\mathrm{aOR}=1.25[1.07 ; 1.45])$ and obese $(\mathrm{aOR}=1.47$ $[1.19 ; 1.81])$ individuals, those having frequent cold $(a \mathrm{OR}=1.63[1.37 ; 1.94])$ and those with at least one chronic condition (aOR $=1.35[1.16 ; 1.58]$ ) had more AGE episodes. Living alone was associated with a higher AGE episode rate $(\mathrm{aOR}=1.31[1.09 ; 1.59])$, as well as having pets at home (aOR $=1.23[1.08 ; 1.41])$.
\end{abstract}

Conclusions: Having a better knowledge of AGE determinants will be useful to adapt public health prevention messages.

Keywords: Gastroenteritis, Epidemiology, Risk factors, Population surveillance

\footnotetext{
* Correspondence: thierry.blanchon@upmc.fr

'Sorbonne Université, INSERM, Institut Pierre Louis d'épidémiologie et de Santé Publique, IPLESP, F75012 Paris, France

Full list of author information is available at the end of the article
}

C C The Author(s). 2020 Open Access This article is licensed under a Creative Commons Attribution 4.0 International License, which permits use, sharing, adaptation, distribution and reproduction in any medium or format, as long as you give appropriate credit to the original author(s) and the source, provide a link to the Creative Commons licence, and indicate if changes were made. The images or other third party material in this article are included in the article's Creative Commons licence, unless indicated otherwise in a credit line to the material. If material is not included in the article's Creative Commons licence and your intended use is not permitted by statutory regulation or exceeds the permitted use, you will need to obtain permission directly from the copyright holder. To view a copy of this licence, visit http://creativecommons.org/licenses/by/4.0/ The Creative Commons Public Domain Dedication waiver (http://creativecommons.org/publicdomain/zero/1.0/) applies to the data made available in this article, unless otherwise stated in a credit line to the data. 


\section{Background}

Acute gastroenteritis (AGE) is usually due to a viral infection involving the stomach and the small intestine, and its clinical picture associates diarrhoea and possible vomiting [1]. Although it is rarely fatal in developed countries, AGE still induces significant morbidity and economic costs [2, 3]. A recent study in France estimated an annual number of cases of $21,000,000$, corresponding to a yearly incidence rate of 0.33 case per person [4]. Moreover 95\% of individuals consulting a general practitioner for an acute diarrhoea received a drug prescription [5] and more than $80 \%$ were prescribed a sick leave [6], leading to a substantial societal cost. In a study published in 2014, results showed that stool examinations were positive for at least one enteric virus in 65\% (95\% CI [57-73]) of patients presenting a Winter AGE, with a predominance of noroviruses (49\%) [5].

Effective preventive measures are well-known, such as hand washing education, and current prevention strategies target fragile populations at risk for complications such as elderly [7] or young children [8]. Data available to adapt the prevention strategy have been collected mainly by healthcare professionals like the French Sentinelles network [9], the English General Practice Research Framework [10] or the Continuous Morbidity Registration of the Netherlands Institute of Primary Health Care [11]. However, since AGE is a benign pathology, with only 1 patient out of 3 consulting a physician [4], using only these data is bound to cause a significant bias in the analyzed results.

Through the years, few studies have tried to assess AGE incidence and risk factors at a population level [4, 10, 12-16]. Most of them used a retrospective data collection by conducting a telephone survey of self-reported AGE in the month preceding the phone call $[4,12,14,16]$. There have been some prospective studies on AGE conducted on the general population, but focused mainly on incidence and not on risk factors $[17,18]$.

The objective of this study was to characterize risk factors associated with the occurrence of AGE during winter on the general population in France. A better understanding of the profile of people having AGE among general population would help to develop more efficient and targeted public health actions.

\section{Methods}

\section{Design and study population}

We conducted an observational prospective study using data from the web-based GrippeNet.fr cohort [19]. GrippeNet.fr is part of a European multicentric project (Influenzanet) for syndromic surveillance during winter in the general population through online systems [20]. Participation is voluntary and anonymous after an online registration on the website. Participants are asked to fill a preliminary survey at registration regarding sociodemographic characteristics, medical history, habits and lifestyle. Then, during each winter season - called season thereafter - typically from November to April, they are invited on a weekly basis, by an email, to report and describe any symptoms on a predefined list that may have occurred in the past week. In every weekly survey, participants could select one, several or none of the symptoms suggested. The list contained the following symptoms: fever, chills, runny or blocked nose, sneezing, sore throat, cough, shortness of breath, headache, muscle/join pain, chest pain, feeling tired or exhausted (malaise), loss of appetite, colored sputum/ phlegm, watery/bloodshot eyes, nausea, vomiting, diarrhoea, stomach ache, other, no symptoms. If they indicate having any symptom, they are invited to complete further information on its nature, duration or intensity. Each week, it was specified that symptoms had to be reported only if they weren't related to any chronic condition. In case of diarrhoea, they must indicate the number of loose stool per day. The participants can report symptoms at any time and as often as they wish.

The representativeness of the GrippeNet.fr population was studied on 2011-2012 season [19]. Although it was not representative of the French general population in terms of age and gender (50-69 years old people and women being overrepresented), all age classes were represented. The GrippeNet.fr population was also found to be more frequently employed, with a higher education level of education than French population. No significant difference was found in terms of rate of studied chronic conditions, such as asthma and diabetes.

\section{Inclusion criteria and study period}

The study was conducted over three seasons: 2014-2015 (from 29 November 2014 to 14 April 2015), 2015-2016 season (from 25 November 2015 to 8 May 2016) and 2016-2017 (from 30 November 2016 to 16 April 2017).

Any individual who filled a preliminary survey was registered as a participant for the season in the GrippeNet.fr study. In order to select only those who actively participated and provided information regularly, we included in our study participants who had filled at least one preliminary survey for the ongoing season, and reported at least three weekly surveys during a season, with at least one before, one during and one after the AGE French epidemic period. The AGE epidemic period of each season was defined by the French Sentinelles network [21]: from December the 1st, 2014 to February the 2nd, 2015 for 2014-2015 season, from January the 4th, 2016 to February the 7th, 2016 for 2015-2016 season and from November the 17th to January the 18th for 2016-2017 season. The 2016-2017 epidemic period started before the beginning of the follow-up (17 November 2016), thus, for this season, we included participants having reported at least two weekly surveys, one during and one after the epidemic period. 


\section{Case definition}

AGE episodes and their duration were identified and reconstructed using symptoms reported by the participants in the weekly surveys.

To be close to the French surveillance data, we select the definition of AGE used by the French Sentinelles network: three or more daily watery (or nearly so) stools for less than 14 days [9]. For each season, a case was defined as a participant having at least one episode of AGE, and a control as a participant having none.

We also conducted a complementary analysis with an alternative definition proposed by an expert group mandated by the WHO (the International Collaboration on Enteric Disease): three or more loose stools or any vomiting in $24 \mathrm{~h}$, but excluding those due to chronic illness causing diarrhoea or vomiting, or due to drugs, alcohol or pregnancy [22].

\section{Participant's characteristics}

Data were collected about gender, age, household composition and residential zip code, allowing us to differentiate urban from rural participants. Questions assessed social mixing in terms of daily contact with a group of people (more than 10 individuals), with children (more than 10), with elderly (more than 10, over 65-year-old), or patients, the use of public transportation and the presence of pets at home. Data were collected on participants' height and weight, making possible the body mass index (BMI) estimation. Smoking status was reported. Chronic conditions were evaluated by asking participants if they had taken drugs for any of the listed conditions: asthma, diabetes, heart condition, kidney condition, immunosuppression. They were also asked about the frequency of common cold or flu-like disease: never or almost never, rare (1 to 2 times a year), or often ( 3 or more).

\section{Statistical analysis}

The participant's characteristics were described by season. The same participant may have participated in one, two or three seasons. To account for this dependency, we used a logistic model using the generalized estimating equations (GEE) approach to identify variables associated with having at least one AGE episode during a season. Variables with a univariate $p$-value below 0.20 were included in the multivariable analysis. We then proceeded with a backward stepwise variables selection, using the Akaike information criterion, until reaching a final model including only variables with a $p$-value below 0.05 . We conducted the same analysis with the alternate definition. All statistical analyses were performed using the R software [23] and geepack package [24].

\section{Ethics approval}

The GrippeNet.fr study was approved by the French Advisory Committee on Information Processing in Material
Research in the Field of Health (authorization 11.565) and by the French National Commission for Computing and Liberties (authorization DR-2012-024). Performing ancillary studies was mentioned in the GrippeNet.fr protocol and in the inclusion survey.

\section{Results}

\section{Participation and population}

During the 2014-2015 season, 3905 (59\%) of the 6632 GrippeNet.fr registered individuals were considered active and were included in the study; 4906 (75\%) of 6515 in 2015-2016; and 5164 (83\%) of 6234 in 2016-2017 (Table 1). Overall they were 13,974 participants included in the study over the three seasons, and among them 3152 individuals were included to the study for the three seasons. During the study period, 385 participants (9.9\%) declared at least one AGE in 2014-2015, 412 (8.4\%) in 2015-2016 and 311 (6\%) in 2016-2017. Mean number of AGE episode per participant are described in Table 1.

Socio-demographic characteristics, exposure and health status were similar for the three seasons (Table 2). The participants were mostly women, $60 \%$ in each season $(n=$ 2326 in the first one, $n=2942$ in the second and $n=3113$ in the third), they lived in urban area for $81 \%$ of them (according to the season, $n=3145, n=3973$ and $n=4161$ ) and were on average 53 years old in the first season, 53.6 in the second and 53 in the third. Almost half of the participants had at least one social exposure: 10 to $11 \%$ with patients, $n=388$ in the first season, $n=476$ the second, $n=555$ in the third, $10 \%$ with elderly, $n=401, n=486$ and $n=537), 31$ to $32 \%$ with a group of people, $n=1230, n=$ 1533 and $n=1677$ ) or 24 to $33 \%$ with children, $n=952$, $n=1213$ and $n=1223)$. Concerning health status, 811 participants (21\%) of the first season, 1079 (22\%) of the second and $1098(21 \%)$ of the third season were treated for at least one comorbidity.

\section{Risk factor analysis}

With univariable analysis (Table 3), we identify several factors associated with the risk of having at least one AGE during a winter season $(p<0.05)$ : season, age, household composition, main activity, having pets, common cold or flu-like disease frequency, being treated for at least one chronic condition, having a respiratory allergy, and BMI.

Regarding adjusted Odds Ratio (aOR) from the final multivariable model (Table 3), compared to individuals between 15 and 60 yo, elderly ( $\geq 60$ yo) tend to have fewer AGE episodes ( $\mathrm{aOR}=0.76,95 \% \mathrm{CI}[0.64 ; 0.89]$ ), as children between 10 and 15 y $(\mathrm{aOR}=0.60$ [0.37;0.98]). Having pets at home is associated with having AGE episode $(\mathrm{aOR}=1.23[1.08 ; 1.41])$. Living alone is also associated with having AGE episode $(\mathrm{aOR}=1.31[1.09 ; 1.59])$ compared to people living with adults. We also highlight 
Table 1 Description of the number of participants included in the study and the number of AGE cases reported per season, using the AGE definition of the French Sentinelles network

\begin{tabular}{|c|c|c|c|}
\hline & Season 2014-2015 & Season 2015-2016 & Season 2016-2017 \\
\hline GrippeNet.fr registered individuals ${ }^{a}, n$ & 6632 & 6515 & 6234 \\
\hline Active participants included in the study, $\mathrm{n}(\%)$ & $3905(59 \%)$ & $4906(75 \%)$ & $5164(83 \%)$ \\
\hline Weekly surveys filled by active participants, $n$ & 75,576 & 100,147 & 82,793 \\
\hline AGE episode reported, $\mathrm{n}$ & 439 & 476 & 336 \\
\hline Participants having at least one AGE episode, n (\%) & $385(9.9 \%)$ & $412(8.4 \%)$ & $311(6.0 \%)$ \\
\hline Mean number of AGE episode per participant having at least one (min - max) & $1.14(1-5)$ & $1.16(1-5)$ & $1.08(1-4)$ \\
\hline Mean number of AGE episode per participant & 0.112 & 0.097 & 0.065 \\
\hline
\end{tabular}

${ }^{a}$ Any GrippeNet.fr participants having filled at least one preliminary survey

${ }^{b}$ GrippeNet.fr participants having filled at least three weekly surveys (one before, one during and one after the AGE epidemic period for the first two seasons, and one during and one after for the last season)

three health characteristics associated with AGE: overweight $(\mathrm{aOR}=1.25[1.07 ; 1.45])$ and obesity $(\mathrm{aOR}=1.47$ [1.19;1.81]) compared to normal BMI, having often $(\mathrm{aOR}=1.63[1.37 ; 1.94])$ or rarely $(\mathrm{aOR}=1.17[1.01 ; 1.36])$ common cold or flu-like disease compared to never, and being treated for at least one chronic condition $(\mathrm{aOR}=$ 1.35 [1.16;1.58]. Participants were less likely to have AGE during the $2015 / 16$ season $(\mathrm{aOR}=0.84$ [0.73; 0.97]) and the $2016 / 17$ season $(\mathrm{aOR}=0.56[0.48 ; 0.65]$ compared to the 2014/15 season.

\section{Complementary analysis}

Using the alternate WHO AGE definition (Table 4), 574 (14.7\%) participants had at least one AGE episode in the 2014-2015 season, 682 (13.9\%) in 2015-2016 and 568 (11.0\%) in 2016-2017. In the final multivariable model, factors associated with at least one AGE episode per season using the previous definition were still significant (Table 4). We identified three additional risk factors: men had less AGE episodes than women $(\mathrm{aOR}=0.81$ [0.72; 0.91]), people with a lower level of education (middle school diploma) tend to have more episodes than people with high school diploma $(\mathrm{aOR}=0.78$ [0.64; $0.95]$ ), a history of respiratory allergy was associated with AGE $(\mathrm{aOR}=1.20[1.07 ; 1.35])$.

\section{Discussion}

This prospective study estimated the frequency of AGE episodes during winter in the French general population and identified risk factors associated with having at least one AGE episode during this period.

Depending on the definition used and the season, between 6 and 14\% of participants presented at least one AGE episode during winter. In Sweden, a study collecting health status data on a weekly basis estimated that $35 \%$ of the participants reported having at least one AGE episode in 2013 [13]. The study however adopted a more inclusive AGE definition than ours, it considered a population where young children were overrepresented, and it focused on a whole year, all factors that may explain the higher reported incidence. Other previous studies in the general population were mostly designed to evaluate a weekly or a monthly incidence rate and did not follow individuals for a long period. Therefore, they do not allow the estimation of the number of individuals having at least one AGE episode during a winter period. Our results show a decrease in the number of AGE episodes observed over the three seasons. This decrease between the 2014-2015 and 2015-2016 seasons is reflected in the national surveillance data from the French GPs' Sentinelles network, which monitors cases of acute gastroenteritis consulting a physician during the winter period. Regarding these data, there were a slight re-increase incidence in 2016-2017, in contrast to the decrease in the number of cases observed in our study. This difference with our data is most likely due to a start of the 2015-2016 gastroenteritis epidemic before the start of the Grippenet.fr surveillance period, explaining that our study may not have accounted for AGE from the early beginning of the epidemic [25].

In our study, we identify some risk factors associated with an AGE episode, previously reported in other studies. We found that elderly people were associated to a lower risk. This association has been shown before, in France [4] and in other developed countries [12, 14, 15, 26]. However, others studies reported that infants tend to have significantly more AGE episode $[4,12,15]$ than adults. We only found this association when using a more inclusive definition for AGE episodes in the complementary analysis. This can mainly be explained by the large underrepresentation of children in the GrippeNet.fr cohort [19], causing a low statistical power. In some previous studies, female gender is found to be positively associated with having an AGE episode [12, 14, 27]. We found this 
Table 2 Socio-demographic characteristics, exposure and health characteristics of participants of the study according to the season

\begin{tabular}{|c|c|c|c|}
\hline Variables & $\begin{array}{l}\text { Season 2014-2015 } \\
\text { n (\%) }\end{array}$ & $\begin{array}{l}\text { Season 2015-2016 } \\
\text { n (\%) }\end{array}$ & $\begin{array}{l}\text { Season 2016-2017 } \\
\text { n (\%) }\end{array}$ \\
\hline \multicolumn{4}{|l|}{ Socio-demographic characteristics } \\
\hline \multicolumn{4}{|l|}{ Gender (m.d. = 0) } \\
\hline Female & $2326(60 \%)$ & $2942(60 \%)$ & $3113(60 \%)$ \\
\hline Male & $1579(40 \%)$ & $1964(40 \%)$ & $2051(40 \%)$ \\
\hline \multicolumn{4}{|l|}{ Age $(m . d .=18)$} \\
\hline$[0-10[$ & $98(3 \%)$ & $188(4 \%)$ & $175(3 \%)$ \\
\hline$[10-15[$ & $104(3 \%)$ & $128(3 \%)$ & $115(2 \%)$ \\
\hline$[15-60[$ & $1970(50 \%)$ & $2541(52 \%)$ & $2660(52 \%)$ \\
\hline$>60$ & $1732(44 \%)$ & $2042(42 \%)$ & $2205(43 \%)$ \\
\hline \multicolumn{4}{|l|}{ Household composition (m.d. $=49$ ) } \\
\hline Living alone & $614(16 \%)$ & 765 (16\%) & $838(16 \%)$ \\
\hline Living with $\geq 1$ child & $1219(31 \%)$ & $1590(33 \%)$ & $1634(32 \%)$ \\
\hline Living with adults only & 2059 (53\%) & $2532(52 \%)$ & $2675(52 \%)$ \\
\hline \multicolumn{4}{|l|}{ Main activity (m.d. $=258$ ) } \\
\hline Working & $1822(48 \%)$ & $2320(48 \%)$ & $2453(48 \%)$ \\
\hline Student & $344(9 \%)$ & $487(10 \%)$ & $456(9 \%)$ \\
\hline Unemployed & $109(3 \%)$ & $133(3 \%)$ & $128(3 \%)$ \\
\hline Retired & $1411(37 \%)$ & $1702(35 \%)$ & $1846(36 \%)$ \\
\hline Stay at home/Sick leave & $148(4 \%)$ & $171(4 \%)$ & $187(4 \%)$ \\
\hline \multicolumn{4}{|l|}{ Level of education (m.d. = 90) } \\
\hline Middle school diploma & $613(16 \%)$ & 707 (15\%) & $814(16 \%)$ \\
\hline High school diploma & $696(18 \%)$ & $861(18 \%)$ & $944(18 \%)$ \\
\hline Higher education & $2223(57 \%)$ & $2807(58 \%)$ & $3043(59 \%)$ \\
\hline Not concerned ${ }^{a}$ & $336(9 \%)$ & $498(10 \%)$ & $343(7 \%)$ \\
\hline \multicolumn{4}{|l|}{ Place of residency (m.d. =0) } \\
\hline Urbain & $3145(81 \%)$ & $3973(81 \%)$ & $4161(81 \%)$ \\
\hline Rural & $760(19 \%)$ & $933(19 \%)$ & $1003(19 \%)$ \\
\hline \multicolumn{4}{|l|}{ Exposure } \\
\hline \multicolumn{4}{|l|}{ Use of public transportation (m.d. $=0$ ) } \\
\hline Yes & $605(15 \%)$ & $770(16 \%)$ & $813(16 \%)$ \\
\hline No & $3300(85 \%)$ & $4136(84 \%)$ & $4351(84 \%)$ \\
\hline \multicolumn{4}{|l|}{ Contacts (m.d. $=0$ ) } \\
\hline Contact with patients & $388(10 \%)$ & $476(10 \%)$ & $555(11 \%)$ \\
\hline Contact with elderly & $401(10 \%)$ & $486(10 \%)$ & $537(10 \%)$ \\
\hline Contact with a group of people $(\geq 10)$ & $1230(31 \%)$ & $1533(31 \%)$ & $1677(32 \%)$ \\
\hline Contact with children & $952(24 \%)$ & $1213(25 \%)$ & $1223(24 \%)$ \\
\hline \multicolumn{4}{|l|}{ Pets at home (m.d. $=22$ ) } \\
\hline None & $2127(55 \%)$ & $2711(55 \%)$ & $2851(55 \%)$ \\
\hline At least one & $1774(45 \%)$ & $2187(45 \%)$ & $2303(45 \%)$ \\
\hline \multicolumn{4}{|l|}{ Health characteristics } \\
\hline \multicolumn{4}{|l|}{ Common colds frequency (m.d. $=358$ ) } \\
\hline Never & $1749(45 \%)$ & $2079(44 \%)$ & $2248(44 \%)$ \\
\hline Rare & $1401(36 \%)$ & $1740(37 \%)$ & $1890(37 \%)$ \\
\hline
\end{tabular}


Table 2 Socio-demographic characteristics, exposure and health characteristics of participants of the study according to the season (Continued)

\begin{tabular}{|c|c|c|c|}
\hline Variables & $\begin{array}{l}\text { Season 2014-2015 } \\
\text { n (\%) }\end{array}$ & $\begin{array}{l}\text { Season 2015-2016 } \\
\text { n (\%) }\end{array}$ & $\begin{array}{l}\text { Season 2016-2017 } \\
\text { n (\%) }\end{array}$ \\
\hline Often & $698(18 \%)$ & 898 (19\%) & $914(18 \%)$ \\
\hline \multicolumn{4}{|l|}{ Smoking status (m.d. = 16) } \\
\hline Non smoker & $3492(90 \%)$ & 4377 (89\%) & 4597 (89\%) \\
\hline Smoker & $406(10 \%)$ & $525(11 \%)$ & $562(11 \%)$ \\
\hline \multicolumn{4}{|l|}{ Comorbidities (m.d. =0) } \\
\hline No comorbidities & 3094 (79\%) & $3827(78 \%)$ & $4066(79 \%)$ \\
\hline At least one comorbidity ${ }^{b}$ & $811(21 \%)$ & $1079(22 \%)$ & $1098(21 \%)$ \\
\hline Treated asthma & $219(6 \%)$ & $319(7 \%)$ & $303(6 \%)$ \\
\hline Treated diabetes & 139 (4\%) & $184(4 \%)$ & $203(4 \%)$ \\
\hline Treated heart condition & $397(10 \%)$ & $501(10 \%)$ & $502(10 \%)$ \\
\hline Treated kidney condition & $22(1 \%)$ & $36(1 \%)$ & $29(1 \%)$ \\
\hline Treated immunosuppression & $109(3 \%)$ & $144(3 \%)$ & $133(3 \%)$ \\
\hline Treated pulmonary condition & $102(3 \%)$ & 139 (3\%) & $124(2 \%)$ \\
\hline \multicolumn{4}{|l|}{ Respiratory allergy (m.d. = 0) } \\
\hline None & 2609 (67\%) & $3267(67 \%)$ & $3378(65 \%)$ \\
\hline At least one & $1296(33 \%)$ & $1639(33 \%)$ & $1786(35 \%)$ \\
\hline \multicolumn{4}{|l|}{ Pregnancy (m.d. = 67) } \\
\hline Yes & $39(1 \%)$ & $56(1 \%)$ & $50(1 \%)$ \\
\hline No & $660(17 \%)$ & $871(18 \%)$ & $962(19 \%)$ \\
\hline Not concerned $^{c}$ & 3191 (82\%) & $3943(81 \%)$ & $4136(80 \%)$ \\
\hline \multicolumn{4}{|l|}{ BMI (m.d. = 229) } \\
\hline Underweight (<18.5) & $185(5 \%)$ & $207(4 \%)$ & $231(5 \%)$ \\
\hline Normal weight ([18.5-25[) & 2208 (57\%) & $2791(58 \%)$ & 2911 (57\%) \\
\hline Overweight ([25-30[) & 1027 (27\%) & $1292(27 \%)$ & $1368(27 \%)$ \\
\hline Obese $(>30)$ & $424(11 \%)$ & $526(11 \%)$ & $576(11 \%)$ \\
\hline
\end{tabular}

m.d. missing data. The number correspond to the total of missing data for both seasons

${ }^{a}$ Children and students not having finished their studies

${ }^{b}$ Participants having responded they are taking medication for at least one of the condition listed below

${ }^{c}$ Women under 15 or above 55 and men

association when using the more inclusive definition. This association is still discussed and not systematically highlighted. Surprisingly, having possible contacts "at risk" during the day (contacts with children, with elderly, with a large group of people and with patients) were never associated with an AGE episode, whereas such associations have been found in several previous studies $[5,28,29]$. The formulation of some survey questions might be too imprecise and induced misinterpretation from participants, for instance the word "contact" is not defined at any time in the survey, as well as the duration of such contact.

Others AGE risk factors studied here have been rarely analyzed in previous work but are expected. To our knowledge, having a chronic condition has not been studied before and identified as a risk factor for AGE episode in general population. Nonetheless, some chronic conditions such as chronic kidney disease [30] or immunosuppression [31] are known to be associated with an increased risk of acute infections. This association might explain the link between overall chronic conditions and AGE episodes. Association between AGE episode and BMI status has not been found before in general population. Although this association may be partly explained by the increased frequency of functional bowel disorders among overweight people [32], participants were supposed to report only new AGE episodes and not include persistent or chronic symptoms. Overweight is already known to be associated with an increased frequency of influenza [33] and further investigation would be needed to investigate its association with AGE. 
Table 3 Factors associated with having at least one AGE episode during a winter season (univariate and multivariate analysis) among the 8811 participants-season, using the AGE definition of the French Sentinelles network

\begin{tabular}{|c|c|c|c|c|c|c|c|}
\hline \multirow[b]{2}{*}{ Variable } & & \multirow[b]{2}{*}{$\mathrm{N}^{*}$} & \multirow[b]{2}{*}{ Case N (\%) } & \multicolumn{2}{|l|}{ univariate analysis } & \multicolumn{2}{|l|}{ multivariate analysis } \\
\hline & & & & OR [IC 95\%] & $p$-value & OR [IC 95\%] & $p$-value \\
\hline \multirow[t]{3}{*}{ Season } & 2014-2015 & 3905 & $385(10 \%)$ & - & $<0.001$ & - & $<0.001$ \\
\hline & 2015-2016 & 4906 & $412(8 \%)$ & $0.83[0.72-0.95]$ & & $0.84[0.73-0.97]$ & \\
\hline & $2016-2017$ & 5164 & $311(6 \%)$ & $0.58[0.50-0.67]$ & & $0.56[0.48-0.65]$ & \\
\hline \multicolumn{8}{|l|}{ Sociodemographic characteristics } \\
\hline \multirow[t]{2}{*}{ Gender } & Female & 8381 & $663(8 \%)$ & - & 0.890 & & \\
\hline & Male & 5594 & $445(8 \%)$ & $1.01[0.88-1.15]$ & & & \\
\hline \multirow[t]{4}{*}{ Age (years) } & 15 to 59 & 7171 & $617(9 \%)$ & - & $<0.001$ & - & $<0.001$ \\
\hline & $<10$ & 461 & $54(12 \%)$ & $1.42[1.04-1.93]$ & & $1.26[0.86-1.85]$ & \\
\hline & 10 to 14 & 347 & $16(5 \%)$ & $0.52[0.32-0.84]$ & & $0.60[0.37-0.98]$ & \\
\hline & $\geq 60$ & 5978 & $420(7 \%)$ & $0.80[0.70-0.92]$ & & $0.76[0.64-0.89]$ & \\
\hline \multirow[t]{3}{*}{ Household composition } & Living with adults only & 7266 & $536(7 \%)$ & - & 0.023 & - & 0.015 \\
\hline & Living alone & 2217 & $208(9 \%)$ & $1.28[1.07-1.54]$ & & $1.31[1.09-1.59]$ & \\
\hline & Living with $\geq 1$ child & 4443 & $361(8 \%)$ & $1.10[0.95-1.28]$ & & $0.98[0.82-1.17]$ & \\
\hline \multirow[t]{5}{*}{ Main activity } & Working & 6595 & $573(9 \%)$ & - & 0.009 & & \\
\hline & Student & 1287 & $91(7 \%)$ & $0.79[0.62-1.01]$ & & & \\
\hline & Unemployed & 370 & $34(9 \%)$ & $1.07[0.72-1.60]$ & & & \\
\hline & Retired & 4959 & $343(7 \%)$ & $0.77[0.67-0.90]$ & & & \\
\hline & Stay at home/Sick leave & 506 & $36(7 \%)$ & $0.82[0.56-1.20]$ & & & \\
\hline \multirow[t]{4}{*}{ Level of education } & High school diploma & 2564 & $211(8 \%)$ & - & 0.545 & & \\
\hline & Middle school diploma & 2211 & $157(7 \%)$ & $0.86[0.68-1.09]$ & & & \\
\hline & Higher education & 7488 & $661(8 \%)$ & $0.99[0.83-1.18]$ & & & \\
\hline & Not concerned & 961 & $77(8 \%)$ & $0.99[0.74-1.31]$ & & & \\
\hline \multirow[t]{2}{*}{ Place of residency } & Rural & 2696 & $198(7 \%)$ & - & 0.269 & & \\
\hline & Urban & 11,279 & $910(8 \%)$ & 1.10 [0.93-1.30] & & & \\
\hline \multicolumn{8}{|l|}{ Exposure } \\
\hline \multirow[t]{2}{*}{ Use of public transportation } & No & 11,787 & $937(8 \%)$ & - & 0.876 & & \\
\hline & Yes & 2188 & $171(8 \%)$ & $0.99[0.83-1.18]$ & & & \\
\hline \multirow[t]{2}{*}{ Pets at home } & None & 7689 & $552(7 \%)$ & - & $<0.001$ & - & $<0.001$ \\
\hline & At least one & 6264 & $555(9 \%)$ & $1.26[1.11-1.43]$ & & $1.23[1.08-1.41]$ & \\
\hline \multirow[t]{2}{*}{ Contact with patients } & No & 12,556 & $978(8 \%)$ & - & & & \\
\hline & Yes & 1424 & $130(9 \%)$ & 1.19 [0.98-1.44] & 0.083 & & \\
\hline \multirow[t]{2}{*}{ Contact with elderly } & No & 12,551 & $994(8 \%)$ & - & & & \\
\hline & Yes & 1424 & $114(8 \%)$ & $1.00[0.81-1.23]$ & 0.992 & & \\
\hline \multirow[t]{2}{*}{ Contact with a group of people } & No & 9535 & $730(8 \%)$ & - & & & \\
\hline & Yes & 4440 & $378(9 \%)$ & $1.12[0.98-1.28]$ & 0.092 & & \\
\hline \multirow[t]{2}{*}{ Contact with children } & No & 10,587 & $855(8 \%)$ & - & & & \\
\hline & Yes & 3388 & $253(7 \%)$ & $0.93[0.80-1.08]$ & 0.325 & & \\
\hline \multicolumn{8}{|l|}{ Health characteristics } \\
\hline \multirow[t]{3}{*}{ Common cold frequency } & Never & 6076 & $399(7 \%)$ & - & & - & $<0.001$ \\
\hline & Rare & 5031 & $399(8 \%)$ & $1.21[1.04-1.40]$ & $<0.001$ & $1.17[1.01-1.36]$ & \\
\hline & Often & 2510 & $287(11 \%)$ & $1.79[1.52-2.11]$ & & $1.63[1.37-1.94]$ & \\
\hline Smoking status & Non smoker & 12,466 & 973 (8\%) & - & 0.178 & & \\
\hline
\end{tabular}


Table 3 Factors associated with having at least one AGE episode during a winter season (univariate and multivariate analysis) among the 8811 participants-season, using the AGE definition of the French Sentinelles network (Continued)

\begin{tabular}{|c|c|c|c|c|c|c|c|}
\hline & & & & univariate analysis & & multivariate analysis & \\
\hline & Smoker & 1493 & $133(9 \%)$ & $1.15[0.94-1.41]$ & & & \\
\hline \multirow[t]{8}{*}{ Comorbidities $^{\mathrm{a}}$} & No comorbidities & 10,987 & $810(7 \%)$ & - & $<0.001$ & - & $<0.001$ \\
\hline & At least one comorbidity & 2988 & $298(10 \%)$ & 1.38 [1.19-1.60] & & $1.35[1.16-1.58]$ & \\
\hline & Treated asthma & 841 & $88(10 \%)$ & $1.37[1.07-1.75]$ & 0.012 & & \\
\hline & Treated diabetes & 526 & $61(12 \%)$ & $1.53[1.10-2.12]$ & 0.011 & & \\
\hline & Treated heart condition & 1400 & $133(10 \%)$ & $1.26[1.04-1.53]$ & 0.021 & & \\
\hline & Treated kidney condition & 87 & $5(6 \%)$ & $0.69[0.29-1.64]$ & 0.396 & & \\
\hline & Treated immunosuppression & 386 & $48(12 \%)$ & $1.67[1.20-2.32]$ & 0.023 & & \\
\hline & Treated pulmonary condition & 365 & $34(9 \%)$ & $1.17[0.82-1.69]$ & 0.414 & & \\
\hline \multirow[t]{2}{*}{ Respiratory allergy } & None & 9254 & $689(7 \%)$ & - & 0.008 & & \\
\hline & At least one & 4721 & $419(9 \%)$ & $1.20[1.05-1.37]$ & & & \\
\hline \multirow[t]{4}{*}{ BMI } & Normal weight (18.5 to $24[$ ) & 6923 & $560(7 \%)$ & - & $<0.001$ & - & $<0.001$ \\
\hline & Underweight (< 18.5) & 1126 & $37(6 \%)$ & 0.84 [0.59-1.18] & & $0.72[0.50-1.02]$ & \\
\hline & Overweight (25 to 29) & 3340 & $318(9 \%)$ & 1.23 [1.05-1.43] & & 1.25 [1.07-1.45] & \\
\hline & Obese ( $\geq 30$ ) & 1347 & $171(11 \%)$ & 1.63 [1.33-1.99] & & $1.47[1.19-1.81]$ & \\
\hline
\end{tabular}

aWe only include the gathered variable "At least one comorbidity" in the final model, none of the individual one listed below

Some risk factors associated with an AGE episode in our study are less expected, like having pets at home. This risk factor has been previously studied [5, 34], but it has never been significantly associated with AGE episode. Most of the pets, such as cats, dogs, rodents or reptiles are known to carry some bacteria responsible for acute diarrhoea [35], which could partly explain this association, although the study took place during winter, when AGE are more frequently due to viral agent. The fact that individuals living alone had more episodes, was also surprising. We did not find this association in previous published literature. On the contrary, it was found that having AGE is positively associated with living with young children $[4,5,28]$ or even living with more than 2 other people [4]. This discrepancy may partly be explained by the age difference: people living alone had an average age of 58 years, compared to 52 years for those living with other adults or children, $(p<0.001$, Student$\mathrm{T}$ test). Another explanation may be that people living alone have different eating habits than those living with other adults and children. A report published in 2008 by the Insee (French National Institute of Statistic and Economical Studies) showed that men living alone were more likely to buy pre-prepared dishes or to eat outdoors [36]. Eating at restaurants may increase the mixing of individuals and therefore the possible exposure to viral agents.

\section{Strengths and limitations}

This is the first study evaluating risk factors associated with an AGE episode in France on a prospective cohort, and those factors are evaluated on a very large sample. GrippeNet.fr is an online participatory study, so it is bound to induce some bias in the representativeness of the population followed, as previously shown [19]. This particular mode of recruitment is bound to cause underrepresentation of age group with limited Internet access, such as children or elderly people, notably those living in nursing homes. These two populations may be particularly exposed to AGE epidemics, as vaccination against rotavirus is not recommended as a common practice in France among children, and community life in retirement homes is more likely to lead to outbreaks. Nevertheless, all ages, gender and level of education category are represented in the cohort, thus allowing a study on risk factor. Another important limitation to acknowledge is the design of the GrippeNet.fr cohort that was originally developed to monitor acute winter infections, including gastroenteritis, but was mainly focused on ILI-like episodes. Several potential confounding factors of AGE episodes may not have been collected in the preliminary survey, such as ages of children in household, dietary choices and exposure, or type of pet. Also, communication to potential participants was mainly oriented on ILI-like episodes, and this may have led participants to be less thorough when reporting symptoms not directly related to influenza, like diarrhoea. Nevertheless, the rate of missing data is very low, and results show that French participants contribute very regularly [37], allowing a comprehensive data collection throughout the season and minimizing the risk of undetected AGE episode. 
Table 4 Factors associated with having at least one AGE episode during a winter season (univariate and multivariate analysis) among the 8811 participants-season, using the AGE definition of the WHO expert group

\begin{tabular}{|c|c|c|c|c|c|c|c|}
\hline \multirow{2}{*}{ Variable } & & \multirow[b]{2}{*}{$\mathrm{N}^{*}$} & \multirow[b]{2}{*}{ Case N (\%) } & \multicolumn{2}{|l|}{ univariate analysis } & \multicolumn{2}{|l|}{ multivariate analysis } \\
\hline & & & & OR [IC 95\%] & $p$-value & OR [IC 95\%] & $p$-value \\
\hline \multirow[t]{3}{*}{ Season } & 2014-2015 & 3905 & $574(15 \%)$ & - & $<0.001$ & - & $<0.001$ \\
\hline & $2015-2016$ & 4906 & $682(14 \%)$ & $0.92[0.82-1.03]$ & & $0.92[0.82-1.04]$ & \\
\hline & $2016-2017$ & 5164 & $568(11 \%)$ & $0.71[0.63-0.80]$ & & $0.68[0.60-0.78]$ & \\
\hline \multicolumn{8}{|l|}{ Sociodemographic characteristics } \\
\hline \multirow[t]{2}{*}{ Gender } & Female & 8381 & $1168(14 \%)$ & - & $<0.001$ & - & $<0.001$ \\
\hline & Male & 5594 & $656(12 \%)$ & $0.82[0.74-0.92]$ & & $0.81[0.72-0.91]$ & \\
\hline \multirow[t]{4}{*}{ Age (years) } & 15 to 59 & 7171 & $1018(14 \%)$ & - & & - & \\
\hline & $<10$ & 461 & $146(32 \%)$ & $2.82[2.27-3.51]$ & & $2.33[1.35-4.02]$ & \\
\hline & 10 to 14 & 347 & $60(17 \%)$ & $1.26[0.93-1.71]$ & $<0.001$ & $1.09[0.60-1.95]$ & $<0.001$ \\
\hline & $\geq 60$ & 5978 & $596(10 \%)$ & $0.67[0.59-0.75]$ & & $0.70[0.61-0.80]$ & \\
\hline \multirow[t]{3}{*}{ Household composition } & Living with adults only & 7266 & $833(11 \%)$ & - & & - & \\
\hline & Living alone & 2217 & $309(14 \%)$ & $1.22[1.05-1.43]$ & $<0.001$ & $1.20[1.03-1.41]$ & 0.052 \\
\hline & Living with $\geq 1$ child & 4443 & $675(15 \%)$ & $1.37[1.22-1.53]$ & & $0.95[0.83-1.10]$ & \\
\hline \multirow[t]{5}{*}{ Main activity } & Working & 6595 & 905 (14\%) & - & & & \\
\hline & Student & 1287 & $262(20 \%)$ & $1.61[1.37-1.89]$ & & & \\
\hline & Unemployed & 370 & $53(14 \%)$ & $1.03[0.75-1.42]$ & & & \\
\hline & Retired & 4959 & $494(10 \%)$ & $0.69[0.61-0.78]$ & & & \\
\hline & Stay at home/Sick leave & 506 & $56(11 \%)$ & $0.79[0.58-1.07]$ & $<0.001$ & & \\
\hline \multirow[t]{4}{*}{ Level of education } & High school diploma & 2564 & $316(12 \%)$ & - & & - & \\
\hline & Middle school diploma & 2211 & $221(10 \%)$ & $0.80[0.66-0.97]$ & & $0.78[0.64-0.95]$ & \\
\hline & Higher education & 7488 & $1048(13 \%)$ & $1.05[0.91-1.22]$ & $<0.001$ & $1.00[0.86-1.16]$ & 0.031 \\
\hline & Not concerned & 961 & $228(24 \%)$ & $2.23[1.82-2.74]$ & & 1.19 [0.71-1.99] & \\
\hline \multirow[t]{2}{*}{ Place of residency } & Rural & 2696 & $360(13 \%)$ & - & & & \\
\hline & Urban & 11,279 & $1464(13 \%)$ & $0.97[0.85-1.10]$ & 0.605 & & \\
\hline \multicolumn{8}{|l|}{ Exposure } \\
\hline \multirow[t]{2}{*}{ Use of public transportation } & No & 11,787 & $1450(13 \%)$ & - & & & \\
\hline & Yes & 2188 & $284(13 \%)$ & $0.98[0.85-1.13]$ & 0.815 & & \\
\hline \multirow[t]{2}{*}{ Pets at home } & None & 7689 & $933(12 \%)$ & - & & - & \\
\hline & At least one & 6264 & 889 (14\%) & $1.20[1.08-1.33]$ & $<0.001$ & $1.18[1.06-1.32]$ & 0.009 \\
\hline \multirow[t]{2}{*}{ Contact with patients } & No & 12,556 & $1603(13 \%)$ & - & & & \\
\hline & Yes & 1424 & $221(16 \%)$ & $1.26[1.08-1.48]$ & 0.003 & & \\
\hline \multirow[t]{2}{*}{ Contact with elderly } & No & 12,551 & $1653(13 \%)$ & - & & & \\
\hline & Yes & 1424 & $171(12 \%)$ & $0.90[0.76-1.07]$ & 0.226 & & \\
\hline \multirow[t]{2}{*}{ Contact with a group of people } & No & 9535 & $1212(13 \%)$ & - & & & \\
\hline & Yes & 4440 & $612(14 \%)$ & $1.10[0.99-1.22]$ & 0.091 & & \\
\hline \multirow[t]{2}{*}{ Contact with children } & No & 10,587 & $1489(12 \%)$ & - & & & \\
\hline & Yes & 3388 & $335(16 \%)$ & $1.33[1.18-1.49]$ & $<0.001$ & & \\
\hline \multicolumn{8}{|l|}{ Health characteristics } \\
\hline \multirow[t]{3}{*}{ Common cold frequency } & Never & 6076 & $634(10 \%)$ & - & & - & \\
\hline & Rare & 5031 & $652(13 \%)$ & $1.24[1.10-1.39]$ & $<0.001$ & $1.14[1.01-1.29]$ & $<0.001$ \\
\hline & Often & 2510 & 500 (20\%) & $2.05[1.79-2.34]$ & & $1.58[1.37-1.82]$ & \\
\hline Smoking status & Non smoker & 12,466 & 1624 (13\%) & - & & & \\
\hline
\end{tabular}


Table 4 Factors associated with having at least one AGE episode during a winter season (univariate and multivariate analysis) among the 8811 participants-season, using the AGE definition of the WHO expert group (Continued)

\begin{tabular}{|c|c|c|c|c|c|c|c|}
\hline & \multirow[b]{2}{*}{ Smoker } & \multirow[b]{2}{*}{1493} & \multirow[b]{2}{*}{$198(13 \%)$} & \multicolumn{2}{|c|}{ univariate analysis } & \multicolumn{2}{|l|}{ multivariate analysis } \\
\hline & & & & $1.02[0.86-1.20]$ & 0.860 & & \\
\hline \multirow[t]{8}{*}{ Comorbidities $^{a}$} & No comorbidities & 10,987 & $1407(13 \%)$ & - & & - & \\
\hline & At least one comorbidity & 2988 & $417(14 \%)$ & $1.10[0.97-1.25]$ & 0.136 & $1.18[1.03-1.36]$ & 0.004 \\
\hline & Treated asthma & 841 & $138(16 \%)$ & $1.32[1.08-1.62]$ & 0.008 & & \\
\hline & Treated diabetes & 526 & $75(14 \%)$ & $1.10[0.83-1.46]$ & 0.508 & & \\
\hline & Treated heart condition & 1400 & $172(12 \%)$ & $0.94[0.79-1.12]$ & 0.522 & & \\
\hline & Treated kidney condition & 87 & $9(10 \%)$ & $0.73[0.33-1.59]$ & 0.425 & & \\
\hline & Treated immunosuppression & 386 & $68(18 \%)$ & $1.43[1.07-1.91]$ & 0.017 & & \\
\hline & Treated pulmonary condition & 365 & $52(14 \%)$ & $1.08[0.80-1.45]$ & 0.633 & & \\
\hline \multirow[t]{2}{*}{ Respiratory allergy } & None & 9254 & $1131(12 \%)$ & - & & - & \\
\hline & At least one & 4721 & $693(15 \%)$ & $1.23[1.10-1.37]$ & $<0.001$ & $1.20[1.07-1.35]$ & $<0.001$ \\
\hline \multirow[t]{4}{*}{ BMl } & Normal weight (18.5 to $24[$ ) & 6923 & $976(12 \%)$ & - & & - & \\
\hline & Underweight (< 18.5) & 1126 & $93(15 \%)$ & $1.26[1.00-1.60]$ & & $0.99[0.77-1.26]$ & \\
\hline & Overweight (25 to 29) & 3340 & $459(12 \%)$ & $1.00[0.88-1.14]$ & 0.005 & $1.16[1.02-1.33]$ & $<0.001$ \\
\hline & Obese $(\geq 30)$ & 1347 & $240(16 \%)$ & 1.30 [1.10-1.54] & & $1.35[1.13-1.61]$ & \\
\hline
\end{tabular}

"We only include the gathered variable "At least one comorbidity" in the final model, none of the individual one listed below

\section{Conclusions}

This study confirmed some well-known associations between risk-factors and having an AGE episode and found additional others. Our findings may help to target concerned population for future health information campaigns. The study also further showed how online cohorts are powerful instruments to evaluate risk factors for pathologies with a moderate rate of healthcare seeking behavior.

\section{Abbreviations}

AGE: Acute gastroenteritis; BMl: Body mass index; GEE: Generalized estimating eqs.; OR: Odds ratio

\section{Acknowledgements}

The authors would like to thank all those who have participated in the GrippNet.fr data collection since 2012. We also would like to thank Nargis Aslami for her proofreading of the manuscript.

\section{Authors' contributions}

TB supervised the project. ME and CG conducted analysis. ME and TB wrote the manuscript. CG, CS, LR, CT, VC and TH gave a technical support and scientific advices, contributed to interpret the results and reviewed the article. All authors read and approved the final manuscript.

\section{Funding}

This work was supported by public funds from Sorbonne Université, Inserm, Santé publique France and the French National Research Agency (ANR). The funding was not specific for the study described in this article. The funder had no role in study design, data collection, data analysis, data interpretation, writing of the report, or in the decision to submit this article for publication. All researchers' decisions have been entirely independent from funders.

\section{Availability of data and materials}

GrippeNet.fr databases used in this study are not publicly available, in accordance with the authorization we have from the French National Commission on Informatics and Liberty (CNIL, authorization DR-2012-024).
The datasets used and/or analysed during the current study are available from the authors on reasonable request.

\section{Ethics approval and consent to participate}

The consent procedure was informed and implied through the voluntary and anonymous registration of participants on a dedicated website: https:// www.grippenet.fr, to complete a profile survey. Only an email address is required to participate. Information on confidentiality and data security as well as ethics approval are publicly available on the GrippeNet.fr website (https://www.grippenet.fr/fr/grippenet/confidentialite-et-securitedesdonnees/). Even though ethics approval is not required by the French law for epidemiological data collection in the setting of non-interventional biomedical research, GrippeNet.fr was reviewed and approved by the French Advisory Committee for research on information treatment in the field of health (i.e. CCTIRS, authorization 11.565), and by the French National Commission on Informatics and Liberty (i.e. CNIL, authorization DR-2012-024).

\section{Consent for publication}

Not applicable.

\section{Competing interests}

The authors declare that they have no competing interests.

\section{Author details}

'Sorbonne Université, INSERM, Institut Pierre Louis d'épidémiologie et de Santé Publique, IPLESP, F75012 Paris, France. ²Department of Family Medicine, Faculté de Médecine, Université Paris Descartes, Paris, France. ${ }^{3}$ Département de Médecine Générale, Université Paris Diderot, Paris, France. ${ }^{4}$ Service de Médecine Interne, Hôpital Ambroise-Paré, Assistance Publique Hôpitaux de Paris, APHP, 92100 Boulogne-Billancourt, France. ${ }^{5}$ UFR des Sciences de la Santé Simone-Veil, Université de Versailles

Saint-Quentin-en-Yvelines, 78280 Versailles, France.

Received: 26 February 2020 Accepted: 5 July 2020

Published online: 21 July 2020

\section{References}

1. DuPont HL. Acute infectious diarrhea in immunocompetent adults. N Engl J Med. 2014;370(16):1532-40.

2. Melliez H, Boelle P-Y, Baron S, Mouton Y, Yazdanpanah Y. Morbidity and cost of rotavirus infections in France. Médecine Mal Infect. 2005;35(10):492-9. 
3. Slotwiner-Nie PK, Brandt LJ. Infectious diarrhea in the elderly. Gastroenterol Clin North Am. 2001;30(3):625-35.

4. Van Cauteren D, De Valk H, Vaux S, Le Strat Y, Vaillant V. Burden of acute gastroenteritis and healthcare-seeking behaviour in France: a populationbased study. Epidemiol Infect. 2012;140(4):697-705.

5. Arena C, Amoros JP, Vaillant V, Ambert-Balay K, Chikhi-Brachet R, Jourdan-Da Silva $\mathrm{N}$, et al. Acute diarrhea in adults consulting a general practitioner in France during winter: incidence, clinical characteristics, management and risk factors. BMC Infect Dis. 2014;14:574.

6. Arena C. Epidémiologie des diarrhées virales aiguës chez l'adulte en médecine générale en France. [Epidemiology of acute viral diarrhoea in adults in general medicine in France]. Faculté de médecine Pierre et Marie Curie; 2015.

7. Haut Conseil de la Santé Publique (HCSP). Recommandations relatives aux conduites à tenir devant des gastro-entérites aiguës en établissement d'hébergement pour personnes âgées [Recommendations for action to be taken in acute gastroenteritis in residential care facilities for the elderly]. 2010 janv.

8. Institut national de prévention et d'éducation pour la santé (INPES). Diarrhée chez les nourrissons et les jeunes enfants : comment éviter la déshydratation? [Diarrhea in infants and small children: how to avoid dehydration ?]. 2010.

9. Flahault A, Blanchon T, Dorléans Y, Toubiana L, Vibert JF, Valleron AJ. Virtual surveillance of communicable diseases: a 20-year experience in France. Stat Methods Med Res. 2006;15(5):413-21.

10. Sethi D, Wheeler JG, Cowden JM, Rodrigues LC, Sockett PN, Roberts JA, et al. A study of infectious intestinal disease in England: plan and methods of data collection. Commun Dis Public Health PHLS. 1999;2(2):101-7.

11. de Wit MA, Koopmans MP, Kortbeek LM, van Leeuwen NJ, Bartelds Al, van Duynhoven YT. Gastroenteritis in sentinel general practices. The Netherlands Emerg Infect Dis. 2001;7(1):82-91.

12. Jones TF, MCMillian MB, Scallan E, Frenzen PD, Cronquist AB, Thomas S, et al. A population-based estimate of the substantial burden of diarrhoeal disease in the United States; FoodNet, 1996-2003. Epidemiol Infect. 2007; 135(2):293-301.

13. Edelstein M, Merk H, Deogan C, Carnahan A, Wallensten A. Quantifying the incidence and cost of acute gastrointestinal illness in Sweden, 2013-2014. Epidemiol Infect. 2016;144(13):2831-9.

14. Hall GV, Kirk MD, Ashbolt R, Stafford R, Lalor K. Frequency of infectious gastrointestinal illness in Australia, 2002: regional, seasonal and demographic variation. Epidemiol Infect. 2006;134(1):111-8.

15. de Wit MA, Koopmans MP, Kortbeek LM, Wannet WJ, Vinjé J, van Leusden F, et al. Sensor, a population-based cohort study on gastroenteritis in the Netherlands: incidence and etiology. Am J Epidemiol. 2001;154(7):666-74.

16. Sargeant JM, Majowicz SE, Snelgrove J. The burden of acute gastrointestinal illness in Ontario, Canada, 2005-2006. Epidemiol Infect. 2008;136(4):451-60.

17. Tam CC, Rodrigues LC, Viviani L, Dodds JP, Evans MR, Hunter PR, et al. Longitudinal study of infectious intestinal disease in the UK (IID2 study): incidence in the community and presenting to general practice. Gut. 2012; 61(1):69-77.

18. Wheeler JG, Sethi D, Cowden JM, Wall PG, Rodrigues LC, Tompkins DS, et al. Study of infectious intestinal disease in England: rates in the community, presenting to general practice, and reported to national surveillance. The Infectious Intestinal Disease Study Executive. BMJ. 1999:318(7190):1046-50.

19. Debin M, Turbelin C, Blanchon T, Bonmarin I, Falchi A, Hanslik T, et al. Evaluating the feasibility and participants' representativeness of an online nationwide surveillance system for influenza in France. PLoS One. 2013;8(9):e73675.

20. Paolotti D, Carnahan A, Colizza V, Eames K, Edmunds J, Gomes G, et al. Web-based participatory surveillance of infectious diseases: the Influenzanet participatory surveillance experience. Clin Microbiol Infect. 2014;20(1):17-21.

21. Costagliola D, Flahault A, Galinec D, Garnerin P, Menares J, Valleron AJ. A routine tool for detection and assessment of epidemics of influenza-like syndromes in France. Am J Public Health. 1991;81(1):97-9.

22. Majowic SE, Hall G, Scallan E, Adak GK, Gauci C, Jones TF, et al. A common, symptombased case definition for gastroenteritis. Epidemiol Infect. 2008;136(7):886-94.

23. R Development Core Team. R: A language and environment for statistical computing. Vienna: R Foundation for Statistical Computing; 2008. Available on: http://www.R-project.org.

24. Halekoh U, Højsgaard S, Yan J. The R Package geepack for Generalized Estimating Equations. J Stat Softw. 2006;15(2):1-11.
25. Réseau Sentinelles. Historic of epidemics of acute diarrhea [Internet]. [cited 2 juin 2020]. Available from: https://www.sentiweb.fr/france/en/? page= epidemics.

26. Majowicz SE, Horrocks J, Bocking K. Demographic determinants of acute gastrointestinal illness in Canada: a population study. BMC Public Health. 2007;7:162.

27. Majowicz SE, Doré K, Flint JA, Edge VL, Read S, Buffett MC, et al. Magnitude and distribution of acute, self-reported gastrointestinal illness in a Canadian community. Epidemiol Infect. 2004;132(4):607-17.

28. Letrilliart L, Desenclos JC, Flahault A. Risk factors for winter outbreak of acute diarrhoea in France: case-control study. BMJ. 1997;315(7123):1645-9.

29. Yazdanpanah Y, Beaugerie L, Boëlle PY, Letrilliart L, Desenclos JC, Flahault A. Risk factors of acute diarrhoea in summer--a nation-wide French casecontrol study. Epidemiol Infect. 2000;124(3):409-16.

30. Dalrymple LS, Go AS. Epidemiology of acute infections among patients with chronic kidney disease. Clin J Am Soc Nephrol CJASN. 2008;3(5):1487-93.

31. Ison MG, Hayden FG. Viral infections in immunocompromised patients: what's new with respiratory viruses? Curr Opin Infect Dis. 2002;15(4):355-67.

32. Ho W, Spiegel BMR. The relationship between obesity and functional gastrointestinal disorders. Gastroenterol Hepatol. 2008;4(8):572-8.

33. Punpanich W, Chotpitayasunondh T. A review on the clinical spectrum and natural history of human influenza. Int J Infect Dis IJID Off Publ Int Soc Infect Dis. 2012;16(10):e714-23.

34. Kuusi M, Aavitsland P, Gondrosen B, Kapperud G. Incidence of gastroenteritis in Norway-a population-based survey. Epidemiol Infect. 2003:131(1):591-7.

35. Chuard C. [Pet-associated infections]. Rev Med Suisse. 2009;5(220):1985-90.

36. Institut National de la Statistique et des Etudes Economiques (INSEE). Enquêtes sur le budget des familles 2001 et 2006 [Family Budget Surveys 2001 and 2006]. 2008 . Report No.: 1194.

37. Bajardi P, Paolotti D, Vespignani A, Eames K, Funk S, Edmunds WJ, et al. Association between Recruitment Methods and Attrition in Internet-Based Studies. Plos One. 2014;9(12):e114925.

\section{Publisher's Note}

Springer Nature remains neutral with regard to jurisdictional claims in published maps and institutional affiliations.

Ready to submit your research? Choose BMC and benefit from:

- fast, convenient online submission

- thorough peer review by experienced researchers in your field

- rapid publication on acceptance

- support for research data, including large and complex data types

- gold Open Access which fosters wider collaboration and increased citations

- maximum visibility for your research: over $100 \mathrm{M}$ website views per year

At BMC, research is always in progress.

Learn more biomedcentral.com/submissions 